\title{
STUDI KARAKTERISASI FISIOLOGI CENDAWAN ENTOMOPATOGEN Metarhizium SPp DARI BERBAGAI RIZOSFER TANAMAN HORTIKULTURA KOTA PADANGSIDIMPUAN
}

\author{
Muhammad Agung Permadi ${ }^{1 *}$, Amir Mahmud ${ }^{1)}$, Mukhlis ${ }^{1)}$, Rafiqah Amanda Lubis ${ }^{1)}$, \\ M. Tedi Faisal ${ }^{1)}$
} 1) Fakultas Pertanian Universitas Muhammadiyah Tapanuli Selatan, Padangsidimpuan 22716
e-mail: muhammad.agungp@um-tapsel.ac.id.

\begin{abstract}
Entomopathogenic fungi are bioinsecticides used to control insect pests. Entomopathogenic fungi can found in the rhizosphere area of plants. This study aims to determine the germination, sporulation, and colonization of Metarhizium spp that are found in the various horticultural plants' rhizosphere of Padangsidimpuan. Metarhizium spp used were MetCP, MetKP, MetMP, MetKPP, MetSP, MetJP, MetTP. This research conducted in the Agrotechnology Laboratory of the Faculty of Agriculture, Universitas Muhmmadiyah Tapanuli Selatan. The study used a completely randomized design (CRD). The results showed that the highest germination rate at 6 hours after inoculation (HAI) founded in MetKPP of $31.05 \%$. MetKPP also had the highest germination rate of $37.43 \%$ on 24 HAI. The highest diameter growth founded in MetKP, which was $5.50 \mathrm{~cm}$ at 14 HAI. The highest conidia density was $1,821 \times 10^{6}$ conidia/ml, found in MetMP, significantly different from MetCP, which had the lowest conidia density that was $1.169 \times 10^{6}$ conidia $/ \mathrm{ml}$.
\end{abstract}

Keywords: germination, colonization, sporulation, conidia growth

\begin{abstract}
Abstrak
Cendawan entomopatogen merupakan salah satu jenis bioinsektisida yang digunakan untuk mengendalikan hama serangga. Cendawan entomopatogen dapat ditemukan di daerah rizosfer tanaman. Penelitian ini bertujuan untuk mengetahui, daya kecambah, sporulasi dan kolonisasi Metarhizium spp yang terdapat pada berbagai rizosfer tanaman hortikultura Kota Padangsidimpuan. Isolat cendawan Metarhizium spp yang digunakan adalah MetCp, MetKp, MetMp, MetKpp, MetSp, MetJp, MetTp. Penelitian ini dilaksanakan di Laboratotorium Agroteknologi Fakultas Pertanian Universitas Muhammadiyah Tapanuli Selatan.Penelitian menggunakan rancangan acak lengkap (RAL). Hasil penelitian menunjukkan bahwa daya kecambah tertinggi pada 6 JSI terdapat pada isolat cendawan MetKpp sebesar 31,05\%. Sedangkan pada 24 JSI isolat cendawan MetKpp juga memiliki daya kecambah tertinggi yaitu sebesar 37,43 \%. Pada 14 HSI pertumbuhan diameter tertinggi terdapat pada isolat cendawan MetKp yaitu sebesar 5,50 $\mathrm{cm}$. Kerapatan konidia tertinggi terdapat pada isolat cendawan MetMp sebesar 1,821 x $10^{6} \mathrm{konidia} / \mathrm{ml}$, berbeda nyata dengan isolat cendawan MetCP yang memiliki kerapatan konidia yang terendah yaitu $1,169 \times 10^{6} \mathrm{konidia} / \mathrm{ml}$.
\end{abstract}

Kata kunci: daya kecambah, kolonisasi, sporulasi, pertumbuhan konidia

\section{PENDAHULUAN}

Pengendalian hayati adalah penggunaan organisme bermanfaat untuk membatasi atau mengendalikan populasi hama. Kelompok makhluk hidup ini juga disebut dengan musuh alami atau agens hayati yaitu predator, parasitoid dan patogen. Cendawan entomopatogen termasuk ke dalam kelompok patogen serangga. Cendawan entomopatogen menyebabkan penyakit dan kematian pada serangga. Umumnya cendawan entomopatogen memiliki sifat patogen fakultatif atau obligat. Pada kondisi lingkungan yang tidak menguntungkan/ekstrim atau kerapatan inang 
yang rendah cendawan entomopatogen bertahan di dalam tanah membentuk spora.

Langkah awal dalam penggunaan cendawan entomopatogen sebagai agens hayati dan ekspansinya sebagai bioinsektisida adalah eksplorasi. Selanjutnya adalah karakterisasi fisiologi dari masing-masing cendawan yang didapatkan dan uji virulensi dari cendawan tersebut. Penelitian ini bertujuan untuk mempelajari karakterisasi fisiologi cendawan entomopatogen Metarhizium spp. dari berbagai rizosfer tanaman hortikultura di Kota Padangsidimpuan.

Metarhizium anisopliae merupakan salah satu cendawan entomopatogen yang sering dimanfaatkan untuk mengendalikan serangga hama. Keefektifan cendawan ini telah diuji terhadap beberapa jenis hama diantaranya nimfa Nezara viridula (Hemiptera: Pentatomidae) (Permadi dkk., 2018), larva Crocodolomia pavonana (Hasyim dkk., 2009), larva Spodoptera litura (Widyanti, 2009), larva Spodoptera exigua (Lepidoptera: Noctuidae) (Freed et al., 2012), larva Chilo sacchariphagus (Lepidoptera: Crambidae) (Sianturi dkk., 2014), imago N. viridula (Hemiptera: Pentatomidae) (Permadi dkk., 2019) dan Diaphorina citri (Hemiptera: Liviidae) (Permadi dkk., 2017).

Karakterisasi fisiologi meliputi daya kecambah, kecepatan tumbuh koloni cendawan dan sporulasi cendawan. Karakter fisiologi berkaitan dengan kelangsungan hidup dan virulensi cendawan terhadap serangga hama maupun perbanyakan cendawan di laboratorium. Sedangkan sporulasi cendawan berkaitan dengan potensi seberapa efisien cendawan dapat dikembangkan menjadi mikoinsektisida. Cendawan entomopatogen memiliki bermacam isolat atau strain, sehingga masing-masing cendawan entomopatogen yang diperoleh dari tempat berbeda maka memiliki isolat yang berbeda dan karakter fisiologi yang berbeda pula. Melihat pentingnya karakterisasi fisiologi cendawan, maka diperlukan karakterisasi fisiologi cendawan yang diperoleh dari Kota Padangsidimpuan tersebut.

\section{METODE}

Penelitian ini dilaksanakan di Laboratorium Agroteknologi Fakultas Pertanian Universitas Muhammadiyah Tapanuli Selatan. Pengamatan dilakukan pada:

\section{Karakterisasi fisiologis cendawan entomopatogen}

Karakterisasi secara fisiologi dilakukan pada masing-masing cendawan entomopatogen yang sudah dimurnikan. Isolat cendawan yang diuji adalah isolat cendawan Metarhizium spp. yang diperoleh dari rizosfer tanaman hortikultura di Kota Padangsisimpuan. Masing-masing percobaan disusun dalam rancangan acak lengkap (RAL). Setiap perlakuan diulang sebanyak 3 kali. Data yang diperoleh diolah dengan sidik ragam dan dilanjutkan dengan uji DMRT pada taraf nyata 5\%. Isolat cendawan Metarhizium spp. yang digunakan dalam penelitian ini dapat dilihat pada tabel di bawah ini.

Tabel 1. Isolat Cendawan Entomopatogen Metarhizium spp.

\begin{tabular}{lll}
\hline Isolat & Rizosfer Tanaman & \multicolumn{1}{c}{ Lokasi } \\
\hline MetJP & Jagung & Pijorkoling, Kota Padangsidimpuan \\
MetKP & Kedelai & Losung batu, Kota Padangsidimpuan \\
MetTmP & Tomat & Sigulang, Kota Padangsidimpuan \\
MetKPP & K. Panjang & Sigulang, Kota Padangsidimpuan \\
MetSP & Sawi & Sitamiang baru, Kota Padangsidimpuan \\
MetMtP & Mentimun & Purwodadi, Kota Padangsidimpuan \\
MetCP & Cabai & Siloting, Kota Padangsidimpuan \\
\hline
\end{tabular}

\section{Pembuatan Media Perbanyakan}

Prosedur pembuatan media perbanyakan dari kentang atau potato dextrose agar (PDA) dalam penelitian ini adalah kentang 400 gr, akuades sebanyak 1 liter, agar dan dextrose masing- 
masing sebanyak 15 gr dan kloramfenikol sebanyak 1 gr. Selanjutnya PDA cair dimasukkan ke dalam botol schott untuk sterilisasi menggunakan autoklaf.

\section{Daya kecambah konidia}

Evaluasi daya kecambah konidia dilakukan dengan menggunakan PDA cair di dalam tabung reaksi. Media PDA cair dibuat dengan menggunakan bahan kentang 400 gr, akuades 1 liter, dextrose 15 gr dan kloramfenikol sebanyak 1 gr. Kerapatan konidia cendawan yang digunakan dalam pengamatan daya kecambah adalah $10^{5}$ konidia/ml. Daya kecambah konidia cendawan dihitung pada 6 JSI dan 24 JSI (jam setelah inokulasi). Perhitungan konidia menggunakan haemositometer. Pengamatan dilakukan sebanyak tiga kali. Daya Kecambah = (jumlah konidia bercambah/ jumlah konidia diamati) x 100\%

\section{Laju pertumbuhan koloni}

Masing-masing cendawan entomopatogen yang berumur 7 hari dengan diameter $10 \mathrm{~mm}$ diinokulasikan pada media perbanyakan yang diuji dalam cawan petri dan diinkubasikan pada suhu $25^{\circ} \mathrm{C}$. Pengamatan diameter koloni dari masing-masing cendawan diukur setiap setiap hari sampai 14 hari setelah inokulasi.

\section{Sporulasi}

Sporulasi masing-masing jenis cendawan entomopatogen dihitung dengan cara menyiapkan suspensi konidia dengan kerapatan $10^{6} \mathrm{konidia} / \mathrm{ml}$. Untuk masing-masing isolat, $0.1 \mathrm{ml}$ suspensi konidia dimasukan dalam cawan petri (diameter $7 \mathrm{~cm}$ ) yang telah berisi masing-masing berbagai media perbanyakan. Biakan diinkubasikan selama 15 hari pada suhu $25^{\circ} \mathrm{C}$. Setelah 15 hari, biakan pada cawan petri dimasukan ke dalam labu erlemeyer dan ditambahkan $50 \mathrm{ml}$ aquadest steril. Biakan divorteks selama 5 menit, disaring dan diencerkan sampai 4 kali. Kerapatan konidia dari suspensi dihitung menggunakan haemositometer dan rata-rata jumlah konidia dibandingkan antar isolat.

\section{HASIL DAN PEMBAHASAN}

Hasil penelitian menunjukan bahwa daya kecambah isolat cendawan yang diuji menunjukan hasil tidak nyata pada 6 JSI dan 24 JSI. Daya kecambah yang paling tinggi terdapat pada isolat cendawan MetKP berturut-turut sebesar 31,05\% dan 37,43\% pada 6 JSI dan 24 JSI. Daya kecambah terendah terdapat pada konidia isolat cendawan MetSP yaitu 17,48\% pada 6 JSI dan $24,85 \%$ pada 24 JSI.

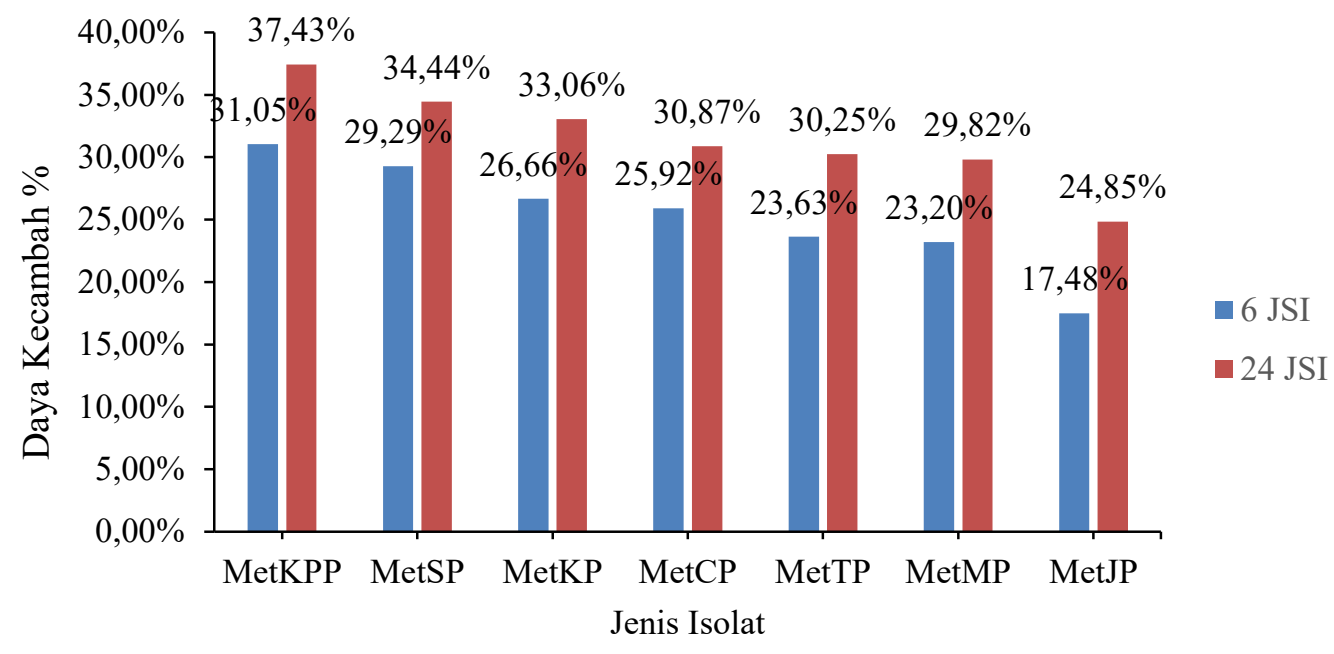

Gambar 1. Daya kecambah isolat cendawan Metarhizium spp (JSI = jam setelah inkubasi) 


\section{Pertambahan Diameter Koloni}

Hasil penelitian menunjukkan bahwa terdapat perbedaan pertumbuhan diameter koloni cendawan dengan rata-rata periode inkubasi adalah 3 hari setelah inkubasi (HSI). Hasil pengamatan pada 3 HSI, 4 HSI, 6 HSI, 7 HSI dan 13 HSI memperlihatkan perbedaan nyata dimana pertumbuhan koloni tertinggi terdapat pada isolat cendawan MetKP dengan rata-rata diameter koloni sebesar 5,25 cm. Pertumbuhan koloni cendawan terendah terdapat pada isolat cendawan MetMP dengan rata-rata diameter koloni sebesar 4,55 cm. Tetapi pada 5 HSI, 8 HSI sampai 12 HSI dan 14 HSI tidak memperlihatkan adanya perbedaan nyata.
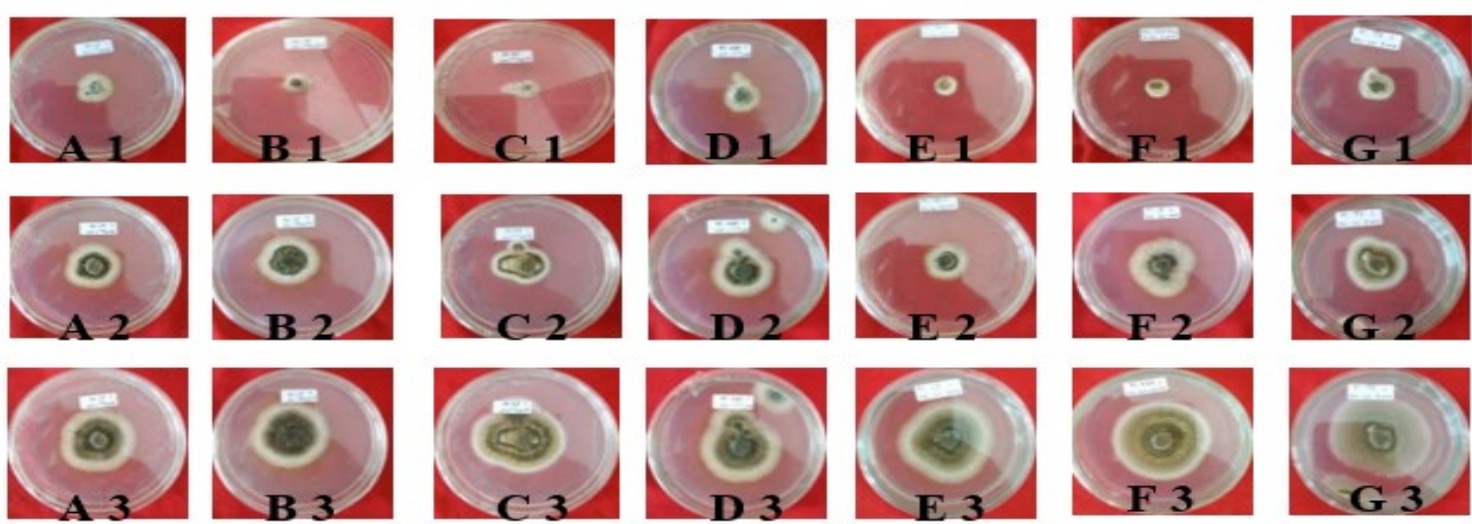

Gambar 3. Pertumbuhan harian koloni isolat Metarhizium spp, (A1) MetCP 3 HSI, (A2) MetCP 9 HSI, (A3) MetCP 14 HSI, (B1) MetJP 3 HSI, (B2) MetJP 9 HSI, (B3) MetJP 14 HSI, (C1) MetKP 3 HSI, (C2) MetKP 9 HSI, (C3) MetKP 14 HSI, (D1) MetMP 3 HSI, (D2) MetMP 9 HSI, (D3) MetMP 14 HSI, (E1) MetSP 3 HSI. (E2) MetSP 9 HSI, (E3) MetSP 14 HSI, (F1) MetKPP 3 HSI. (F2) MetKPP 6 HSI. (F3) MetKPP 14 HSI, (G1) MetTP 3 HSI, (G2) MetTP 9 HSI. (G3) MetTP 14 HSI.

Tabel 2. Ukuran Diameter Harian Metarhizium spp (cm)

\begin{tabular}{|c|c|c|c|c|c|c|c|c|c|c|c|c|}
\hline \multirow{2}{*}{$\begin{array}{l}\text { Jenis } \\
\text { Isolat }\end{array}$} & \multicolumn{12}{|c|}{ Hari ke- } \\
\hline & 3 & 4 & 5 & 6 & 7 & 8 & 9 & 10 & 11 & 12 & 13 & 14 \\
\hline MetCP & $2,05 \mathrm{a}$ & $2,25 \mathrm{ab}$ & $2,62 \mathrm{a}$ & $2,92 \mathrm{a}$ & $3,17 \mathrm{ab}$ & $3,47 \mathrm{a}$ & $3,70 \mathrm{a}$ & $4,07 \mathrm{a}$ & $4,27 \mathrm{a}$ & $4,52 \mathrm{a}$ & $4,82 \mathrm{ab}$ & $5,10 \mathrm{a}$ \\
\hline MetJP & $2,00 \mathrm{a}$ & $2,25 \mathrm{ab}$ & $2,55 \mathrm{a}$ & $2,82 \mathrm{ab}$ & $3,20 \mathrm{ab}$ & $3,50 \mathrm{a}$ & $3,90 \mathrm{a}$ & $4,05 \mathrm{a}$ & $4,37 \mathrm{a}$ & $4,62 \mathrm{a}$ & $4,90 \mathrm{ab}$ & $5,12 \mathrm{a}$ \\
\hline MetKP & $1,97 \mathrm{a}$ & $2,35 \mathrm{a}$ & $2,65 \mathrm{a}$ & $3,02 \mathrm{a}$ & $3,27 \mathrm{a}$ & $3,67 \mathrm{a}$ & $3,92 \mathrm{a}$ & $4,27 \mathrm{a}$ & $4,55 \mathrm{a}$ & $4,92 \mathrm{a}$ & $5,25 \mathrm{ab}$ & $5,50 \mathrm{a}$ \\
\hline MetMP & $1,97 \mathrm{a}$ & $2,25 \mathrm{ab}$ & $2,62 \mathrm{a}$ & $3,00 \mathrm{a}$ & $3,20 a b$ & $3,45 \mathrm{a}$ & $3,72 \mathrm{a}$ & $3,92 \mathrm{a}$ & $4,12 \mathrm{a}$ & $4,35 \mathrm{a}$ & $4,55 \mathrm{~b}$ & $4,92 \mathrm{a}$ \\
\hline MetSP & $1,80 \mathrm{ab}$ & $2,25 \mathrm{ab}$ & $2,57 \mathrm{a}$ & $2,87 \mathrm{a}$ & $3,17 \mathrm{ab}$ & $3,42 \mathrm{a}$ & $3,85 \mathrm{a}$ & $4,17 \mathrm{a}$ & $4,45 \mathrm{a}$ & $4,70 \mathrm{a}$ & $4,97 \mathrm{a} \mathrm{b}$ & $5,22 \mathrm{a}$ \\
\hline MetKPP & $1,62 \mathrm{~b}$ & $2,0 \mathrm{ab}$ & $2,30 \mathrm{a}$ & $2,67 a b$ & $2,97 \mathrm{ab}$ & $3,22 \mathrm{a}$ & $3,60 \mathrm{a}$ & $3,90 \mathrm{a}$ & $4,17 \mathrm{a}$ & $4,67 \mathrm{a}$ & $4,97 \mathrm{a} \mathrm{b}$ & $5,37 \mathrm{a}$ \\
\hline MetTP & $1,60 \mathrm{~b}$ & $1,95 \mathrm{~b}$ & $2,37 \mathrm{a}$ & $2,52 \mathrm{~b}$ & $2,82 \mathrm{~b}$ & $3,22 \mathrm{a}$ & $3,52 \mathrm{a}$ & $3,80 \mathrm{a}$ & $4,15 \mathrm{a}$ & $4,57 \mathrm{a}$ & $4,87 \mathrm{a} \mathrm{b}$ & $5,22 \mathrm{a}$ \\
\hline
\end{tabular}

Keterangan : Angka yang diikuti huruf yang sama pada kolom yang sama tidak berbeda nyata menurut uji Duncan pada taraf nyata $5 \%$.

\section{Kerapatan konidia}

Hasil pengamatan kerapatan konidia isolat cendawan Metarhizium spp setelah 14 HSI menunjukkan perbedaan nyata pada masing-masing jenis cendawan (Tabel 3).

Tabel 3. Kerapatan Konidia Metarhizium spp

\begin{tabular}{cc}
\hline Jenis Cendawan & Kerapatan Konidia \\
\hline MetCP & $1,169 \times 10^{6} \mathrm{~b}$ \\
MetJP & $1,746 \times 10^{6} \mathrm{a}$ \\
MetKP & $1,506 \times 10^{6} \mathrm{ab}$ \\
MetMP & $1,821 \times 10^{6} \mathrm{a}$ \\
MetSP & $1,640 \times 10^{6} \mathrm{a}$ \\
MetKPP & $1,730 \times 10^{6} \mathrm{a}$ \\
MetTP & $1,493 \times 10^{6} \mathrm{ab}$ \\
\hline
\end{tabular}

Keterangan: Angka yang diikuti huruf sama pada kolom yang sama tidak berbeda nyata menurut uji Duncan pada taraf nyata $5 \%$ 


\section{Pembahasan}

Perbedaan karakter fisiologi yang tedapat antar isolat cendawan entomopatogen Metarhizium spp yang diuji disebabkan oleh karakter masing-masing isolat itu sendiri atau faktor genetik. Masing-masing cendawan memiliki kemampuan pertumbuhan dan perkembangan yang berbeda tergantung pada spesies dan isolat cendawan. Selain sumber isolat, sistem pertanian yang digunakan juga dapat mempengaruhi fisiologis cendawan entomopatogen. Sistem pertanian organik menyebabkan tanah tetap sehat karena penambahan bahan organik ke dalam tanah. Margolang dkk. (2015) mengungkapkan bahwa pengaplikasian sistem pertanian organik dapat memperbaiki sifat biologi tanah, termasuk mikroorganisme yang berada dalam tanah. Sedangkan penggunaan pestisida dan pupuk sintetik dapat merusak kesuburan tanah dan tekstur tanah. Mikroorganisme di dalam tanah berangsur mengalami kematian akibat paparan pestisida dan pupuk sintetik. Eksistensi cendawan entomopatogen yang berada dalam tanah sangat tergantung dengan teknik budidaya tanaman dan frekuensi penggunaan pestisida (Sapieha-Waszkiewics et al., 2005). Daya kecambah atau viabilitas adalah parameter yang penting untuk diketahui, sebab daya kecambah menentukan keberhasilan cendawan untuk tumbuh ke tahap selanjutnya. Luas diameter akan menentukan luas bidang yang akan menjadi tempat tumbuhnya konidia. Dan sporulasi akan menentukan banyak konidia yang dihasilkan cendawan. Pada umumnya semakin luas bidang permukaan koloni cendawan maka cendawan tersebut akan menghasilkan lebih banyak konidia. Perbedaan media tumbuh juga akan menyebabkan perbedaaan viabilitas cendawan (Permadi dkk., 2020).

\section{KESIMPULAN}

Masing-masing isolat cendawan Metarhizium spp yang diuji tidak memiliki perbedaan daya kecambah yang nyata, baik pada 6 JSI maupun 24 JSI. Diameter koloni isolat cendawan entomopatogen Metarhizium spp pada 14 HSI berkisar antara 4,92-5,5 cm. Kerapatan konidia tertinggi berasal dari isolat cendawan MetMP, sedangkan isolat cendawan MetCP menghasilkan kerapatan konidia terendah.

\section{UCAPAN TERIMA KASIH}

Penulis mengucapkan terima kasih kepada DRPM Dikti yang telah membantu pendanaan penelitian ini pada skema PDP (penelitian dosen pemula) tahun anggaran 2019 2020 sehingga penelitian dapat terlaksana. Penulis juga mengucapkan terimakasih kepada Universitas Muhammadiyah Tapanuli Selatan yang telah mendukung penulis dalam pelaksaaan penelitian ini.

\section{DAFTAR PUSTAKA}

Freed, S., M. A. Saleem, M. B. Khan, and M. Naeem. (2012). "Prevalence and effectiveness of Metarhizium anisoplie against Spodoptera exigua (Lepidoptera: Noctuidae) in Southern Punjab, Pakistan," J Zoology Pakistan, vol. 44, no. 3, pp. 753-758

Hasyim, A., Nuraida, and Trizelia. (2009). "Patogenisitas jamur entomopatogen terhadap stadia telur dan larva hama kubis Crocidolomia pavonana Fabricius," J. Hortikultura, vol. 19 , no. 3 , pp. 334-343.

Margolang, R.D., Jamilah, M. Sembiring. 2015). "Karakteristik beberapa sifat fisik, kimia, dan biologi tanah pada sistem pertanian organik," J. Onl Agroteknologi, vol. 3, no. 2, pp. 717-723, 2015.

Permadi, M.A. (2017) "Pemanfaatan cendawan Beauveria bassiana (Bals.) Vuill. Sebagai miko-insektisida terhadap kutu loncat jeruk Diaphorina citri Kuw.(Hemiptera: Liviidae)," Biolink, vol. 4, no 1, pp. 82-89. 
Permadi, M.A., R. A. Lubis RA, and D. Sari. (2018). "Virulensi beberapa isolat cendawan entomopatogen terhadap nimfa kepik hijau Nezara viridula Linn.(Hemiptera: Pentatomidae),". J. Agrohita, vol 2, no. 2, pp. 52-60.

Permadi, M. A., R. A. Lubis, Mukhlis, I. A. Pahlawan, and S. Abdi. (2019). "Efication of Some Entomopatogen Fungus on Green Ladybug Imago (Nezara Viridula Linnaeus) (Hemiptera: Pentatomidae)," BirEx Journal, vol. 1, no 2, pp. 21-28.

Permadi, M.A., Mukhlis, B. S. Samosir, D. Y. Siregar, and M. Wayni. (2020). "Physiology Characterization of Entomopathogenic Fungi Beauveria bassiana and Metarhizium anisopliae on Different Carbohydrate Sources," in J. Phys.: Conf. Ser., vol. 1477, no. 7, pp. 072007.

Sapieha-Waszkiewics, A., B. Marjanska-Cichon, Z. Piwowarczyk. (2005). "The Occurrence of Entomophatogenic Fungi In The Soil From The Plantations of Black Currant and Aronia," EJPAU, vol. 8, no. 1, pp. 1-8, 2005

Sianturi, N.B., Y. Pangestiningsih, L. Lubis. (2014). "Uji efektivitas jamur entomopatogen Beauveria bassiana (Bals.) dan Metarhizium anisopliae (Metch.) terhadap Chilo sacchariphagus Boj. (Lepidoptera: Pyralidae) di laboratorium," J Onl Agroekoteknologi, vol. 2, no. 4, pp. 1607-1613.

Widianti, D. (2009). "Virulensi beberapa isolat Metarhizium spp terhadap larva Spodoptera litura Fabricius (Lepidoptera: Noctuidae)," Universitas Andalas. 